\title{
Mobilidades, Media (Ções) e Cultura
}

\author{
Emília Araújo, Denise Cogo \& Manuel Pinto
}

Vive-se hoje na Europa e no mundo a efervescência contínua da mobilidade, da deslocação, da viagem, da ida e do regresso.

Por meio de deslocações efetivas e corpóreas, ou por meio de deslocações virtuais, as sociedades atuais são, nas suas estruturas, intrinsecamente constituídas pela potência das mobilidades, pela possibilidade de sair, ir e voltar.

Ao longo dos anos vimos crescer o número de investigações acerca dos motivos pelos quais as pessoas deixam um espaço geográfico. Assistimos, também, ao aumento do número de pesquisas acerca das motivações que levam as pessoas a escolher certos lugares para viver, trabalhar ou passear. As abordagens sobre tais panóplias de motivos e condições são, ainda hoje, válidas.

Todavia, a época atual surge marcada por fenómenos que são agora muito menos lineares do que eram há décadas atrás. As mobilidades não são apenas cada vez mais pluriformes. São também desencadeadas por motivos de uma configuração substancialmente distinta. A esse respeito, podemos falar da própria natureza da política e da forma como esta modela e dispõe os povos à mobilidade e à migração (apenas para ilustração, pensemos na perseguição política e/ ou religiosa). Mas, também podemos mencionar o modo como certos fenómenos sociais, tais como o trabalho, o lazer, a rede de transportes, as redes e os modos de interação familiar ocorrem em espaços cada vez mais móveis. O mesmo pode ser assinalado para o caso dos modos de emergência e manutenção das redes de tráfico humano, catástrofes naturais e/ou humanas, terrorismo ou guerras e conflitos armados. Tais fenómenos apresentam-se hoje com caraterísticas e dinâmicas inscritas na experiência da globalização financeira e informacional, para a qual pouca diferença faz o lugar - entendido em sentido estrito. Todos estão marcados pela variabilidade, flexibilidade, opacidade, incerteza e imprevisibilidade. Às vezes, são mesmo paradoxais.

Além da natureza dos fenómenos ligados à mobilidade e da própria tipologia possível das mobilidades e migrações hoje, destaquem-se, também, a fluidez, a contradição, a fragilidade e a incerteza que marcam os quadros políticos contemporâneos. Estes, observados de um plano macro estrutural, parecem deixar de ter quadros de ação atinentes, por um lado, aos interesses e ideários dos sujeitos humanos e, por outro, aos interesses mobilizadores da própria economia financeira global. Nesta economia outros tipos de mobilidades e migrações se planeiam e descobrem: nas cidades debaixo do chão, debaixo de água, ou para lá da Terra. Nesse sentido, as próprias mobilidades são um dos objetos centrais de consumo, além de constituírem foco de prevenção, estimativa, vigilância e planeamento.

Com efeito, as mobilidades podem ser perspetivadas como um fenómeno social total, pois constituem um entrelaçado de eventos e de processos que ultrapassam o ato 
de movimentação no espaço e no tempo, incluindo processos de acolhimento e integração, assim como de discriminação, seleção e hostilidade. Através delas fluem formas várias de rememoração e classificação (auto e hétero) identitária, recolhendo interpretações e avaliações realizadas sob paradigmas ideológicos específicos.

Sheller e Urry (2006) apresentaram, em meados dos anos noventa, o que denominam ser o "novo paradigma das mobilidades". Os autores assinalavam que, ao contrário das mobilidades que caraterizaram o mundo até aos anos noventa, a sofisticação, o uso generalizado das tecnologias de informação e comunicação e o reforço das interdependências à escala mundial, estão ligados à experiência contínua das mobilidades que marcam as identidades e os estilos de vida na sociedade moderna. Entre outros contributos relacionados com os meios de transporte, estes autores mostraram a pertinência das técnicas de investigação de cariz qualitativo que contribuem para a análise destas novas modalidades de apropriação e vivência do espaço-tempo. No conjunto, elas fornecem conclusões de interesse inequívoco sobre as próprias formas de estar e de experienciar o movimento, a deslocação e o transporte de tipo público e ou privado, como o automóvel. Os autores citados (Sheller \& Urry, 2006) chamaram a atenção para os grandes elementos de caráter estrutural que condicionam e constituem as plataformas de ação política. Adicionalmente, consideraram a importância de pequenos detalhes do quotidiano, concebidos como espaços "onde" se faz história dos sentidos, das emoções e das sensibilidades. Isto é, como espaços "onde" se passa a ação de apropriação e de consumo e se reflete a confluência de gostos, estilos e modos de estar de tipo cada vez mais estandardizado.

Mais recentemente, seguindo paradigmas de cunho neomarxista, outros autores expuseram o caráter perverso das mobilidades, das deslocações, das passagens, uma vez que a elas se ligam, não só novos padrões de estilos de vida, mas também modos de estar com o espaço e com o tempo. Por exemplo, Gehardi (2009) propõe o conceito de mobilidade ambígua, assinalando os lados mais obscuros e difíceis da vida de quem está em quase permanente mobilidade, por obrigação aos modelos de regulação do trabalho e da economia que exigem a disponibilidade total de certos trabalhadores. A mesma autora, juntamente com Pierre (Gehardi \& Pierre, 2013), esclarece que a mobilidade alimenta não só a economia em sentido material, mas também o ethos de trabalho no seio do capitalismo tecnocientífico.

Deste ponto de vista, as mobilidades e as migrações não são apenas uma das narrativas centrais dos tempos atuais que ganha matizes diferentes entre os discursos e as formas de expressão dos vários grupos sociais. São um eixo preponderante de definição identitária dos povos, das sociedades, constituindo, por dentro, os seus próprios percursos e futuros. São, por isso, um eixo determinante de política. Neste quadro imenso de possibilidades abertas às mobilidades, estas acabam frequentemente analisadas a partir de uma perspetiva que as concebe como resultado de encontros aleatórios bem-sucedidos. Isto é, como processos que marcam a fluidez das transações entre povos e nações. Desse modo, configura-se uma representação que, de certa forma, naturaliza a própria mobilidade - a física e a virtual. 
Mas, a abordagem que pretendemos enquanto editores deste número, é também, na linha do debate encetado por Woolley (2014), uma abordagem política que revela algumas das estruturas mobilizadoras desses movimentos e que revela como a prevalência atual de formas mais tradicionais de migração - como ilustrado pelo refugiado que atravessa a fronteira - deixa vislumbrar formas "subversivas" desencadeadas pelos povos de "resistência" aos mecanismos pelos quais opera a globalização, constituindo-se como "lugares" concretos de contradição e dissensão cultural e política, desde logo porque se distinguem mobilidades "obrigadas" e mobilidades "escolhidas"1.

As deslocações massivas que se verificam atualmente rumo à Europa têm mostrado quão relevantes são as mais diversas formas de mobilidade no mundo contemporâneo para a análise dos processos de construção e de negociação identitária dos indivíduos, dos grupos, dos povos. Formas de mobilidade que estão crescentemente ligadas ao poder de penetração e valorização das mais variadas formas de média e tecnologias de informação e comunicação.

Appadurai (1996) considera mesmo que estar em deslocação constitui um traço peculiar da narrativa da modernidade, marcada pela experiência penetrante das tecnologias de informação e comunicação, pela capacidade cada vez maior de driblar distâncias e fazer "desaparecer" tempos, seja através do aumento da velocidade de circulação, seja através da hiper-imposição do espaço virtual. No mesmo quadro, afirmaria Bauman que se vive em ambientes crescentemente líquidos (Bauman, 2004).

Deste ponto de vista, emergem novas classificações para os sujeitos desta nova era em que praticamente tudo pode ser nómada, mesmo sem sair do lugar e em que praticamente tudo se pode mudar de lugar, sem quebrar ligações e dependências. Do conjunto destas novas espacialidades e temporalidades surgem inevitavelmente novas formas de experienciar as relações interculturais que acontecem em espaços de tipo crescentemente transnacional, dada a natureza da circulação do próprio capital num mundo que permanece desigual na forma de concentração e distribuição de recursos.

Com efeito, tal como afirma Sheller, pensar as mobilidades nas sociedades modernas não se reduz ao ato de trazer para o plano concetual a noção de fluidez identitária criada nas interseções espaciotemporais. A reflexão e a investigação sobre as mobilidades hoje retomam elementos estruturais como a colonização, o pós-colonialismo ou a globalização (Sheller, 2011, pp. 2-3)

$\mathrm{Na}$ linha da concetualização da cultura como um resultado político-cultural, consoante a proposta de Hall (1997), podemos dizer que a relação entre os média e as mobilidades se evidencia nesta perspetiva da cultura, entendida a partir dos processos de construção e afirmação identitária no espaço e no tempo (por exemplo, bem expressa na experiencia dos trabalhadores móveis). Além das tecnologias digitais, os próprios meios de comunicação, em geral, contribuem para a montagem de narrativas da mobilidade, ao fornecerem informação, mas também ao veicularem imagens, representações e estereótipos sobre quem se move e por que se move e, igualmente, sobre os espaços e os lugares.

' Citamos neste sentido o enquadramento e análise crítica elabora por Woolley (2014), a propósito das abordagens de Appadurai (1996). 
Contava-nos, numa entrevista, um emigrante em França que, estando reformado, costumava cuidar dos netos a residir a cerca de 500 quilómetros de distância. Perguntávamos-lhe como era possível que tal acontecesse: "através do Skype", respondeu, acrescentando, "ficam todos na sala a brincar e nós ficamos ali a falar e a vigiar, vou perguntando o que precisam, a onde devem ir, o que devem fazer naquele tempo em que os pais não estão, estamos todos ligados, também aos serviços do hospital e polícia". A experiência que contamos refere-se a um modo de estar cada vez mais típico na sociedade moderna e é interpretável tanto como negativo, como positivo.

Desde alguns anos, os investigadores têm vindo a explorar o modo como os média podem afetar as opiniões dos cidadãos sobre os imigrantes, ou os que se movem em geral, influenciando o seu comportamento relativamente a essas pessoas que chegam. Há também estudos sobre a forma como os média podem influenciar os programas políticos dirigidos às questões das mobilidades e migrações. Algumas pesquisas têm vindo a indicar como os média podem estar a operar a construção de identidade em diversas escalas (individuais, nacionais e transnacionais). No livro Media e Migração, editado por King e Wood (2001), sustenta-se que os média podem não só influenciar, como induzir o caminho próprio migratório, influindo, também, sobre a criação de vários tipos de diásporas. As mobilidades, nesse sentido, significam também complexidade, reforço do planeamento, da organização e do controlo. A circulação de pessoas e a circulação de informação processam-se hoje mediante códigos cada vez mais elaborados de vigilância, para a qual contribuem enormemente as tecnologias digitais. Trata-se de uma vigilância que se faz em resposta à própria evolução do nível de sofisticação dessas tecnologias enquanto elementos essenciais da sociedade global, capitalista e financeira. Mas trata-se, também, de uma resposta à proliferação do medo, por parte das instituições, das populações e dos indivíduos. Esse medo espalha-se, igualmente,como elemento constitutivo pelos interstícios dos tecidos relacionais, em espaços-tempos físicos virtuais, e cria-se e constrói-se através das imagens e conteúdos mediáticos, que circulam velozmente através de todos os espaços virtuais, provocando novas realidades e estímulos à ação.

Uma linha emergente de estudos promete mostrar a multidimensionalidade dos fenómenos de mobilidade e de migração no contexto da reconfiguração e produção de novas (e outras) identidades, face à constituição tecnocientífica da cultura. Tais estudos debruçam-se, por isso, sobre fenómenos como as mediações operadas pelas tecnologias na preparação e durante a experiência de mobilidade e/ou migração. $O$ uso dos meios audiovisuais de acesso rápido, como o telemóvel e outros dispositivos de comunicação, favorecem a criação de espaços heterotópicos de "entretantos" através dos quais se constrói hoje a "aventura do quotidiano", usando a expressão de Michel De Certeau (1990). Em paralelo, outras pesquisas, com origens em várias Ciências Sociais e Humanas, propõem, sob essa mesma égide da transformação cultural inscrita na tripla relação entre movimento-identidade-erosão espaço-tempo, o papel dos média digitais, incluindo redes sociais e outros. Referem, principalmente, o seu papel na constituição das próprias narrativas migratórias, ajudando a desconstruir o seu sentido identitário de nível micro e macrossociológico. Trata-se de investigações que analisam a estrutura, 
a forma e os conteúdos das histórias pessoais murmuradas (e reveladas) "através" dos espaços virtuais e nas quais se espelham os desejos, ressentimentos, e também os agradecimentos, face aos locais de onde se sai, por onde se passa, onde se vai ficando: vídeos, selfies, imagens diversas e sons desempenham papéis cada vez mais profundos na composição (em revelação permanente) dos sujeitos em mobilidade, ao ponto de as próprias histórias biográficas dos sujeitos se assumirem ou como produtos artísticos, ou como elementos desses (Nurse, 2014).

Este número da revista Comunicação e Sociedade reúne textos que discutem as mobilidades e os média, seguindo diversas perspetivas e debruçando-se sobre objetos diferenciados. Dividimos o número em três grandes temas: i) diáspora, dinâmicas de mobilidade e média; ii) mobilidades, culturas e universos tecnológicos e iii) vária.

O primeiro tema integra quatro textos que tocam, de forma mais ou menos profunda, a problemática das migrações e dos mecanismos de marcação e rotulagem que interatuam em situações de contacto cultural, marcado por processos discriminatórios. O espaço da cidade e a sua complexidade em termos de mobilidade sobressai nos dois restantes textos que se inserem neste tema, sendo particularmente relevante observar a referência que fazem os autores à mobilidade como um componente dos estilos de vida e da afirmação de valores.

O texto da autoria de Igor Sacramento e Izamara Machado continua a linha das questões colocadas anteriormente sobre as migrações, mas debatendo, de modo especial, a forma como os média brasileiros trataram a crise do ébola, no caso concreto da mobilidade/receção de pessoas vindas de África. Assinalando o viés colonialista e etnocêntrico existente nos média face a África e à própria doença, os autores demonstram, na base de análise empírica, como os média veiculam imagens e representações estereotipadas e discriminatórias face aos migrantes, especialmente se estes se afiguram permeáveis a conotações que amedrontam, pelo desconhecimento, a própria sociedade.

O texto de Mauricio Nihil Oliveira centra-se na discussão do conceito de e-migrante, assinalando, na base de pesquisa empírica realizada no Uruguai, como as tecnologias de informação e de comunicação configuram tipos específicos de comunicação e de interação entre imigrantes espanhóis e residentes, facilitando a construção de diásporas. $O$ autor está, nesse caminho, especialmente interessado em discutir como as tecnologias de informação e comunicação criam espaços de reforço identitário nos países de receção e de que forma isso se reflete na intensidade e qualidade da participação política no próprio país de acolhimento, mas sobretudo em relação ao país de origem - a Espanha.

No quadro das migrações e da comunicação intercultural, surge-nos o texto de Teresa Alves, que discute as transferências, transações e transmutações identitárias entre Portugal e Brasil, no contexto específico dos programas brasileiros dedicados à comunidade lusa, residente naquele território. Além dos conteúdos explícitos, a autora foca as dimensões mais silenciosas e sonoras das trocas culturais e simbólicas, apresentando uma perspetiva que integra a análise das dimensões coloniais e pós-coloniais.

Felipe Gustsack e Sandra Rocha são os autores do quarto texto, que é dedicado a uma dimensão mais microssociológica das mobilidades. Neste texto procura-se 
esclarecer a relação entre esta dimensão das mobilidades e a emergência de configurações culturais que enformam experiências de vida centradas na procura que os sujeitos sociais empreendem para revelarem as suas subjetividades no espaço público, seguindo mecanismos semelhantes ao da expressão narrativa, neste caso auto identitária. A partir da análise de conteúdo a frases e legendas de autocolantes usados nos automóveis, os autores propõem que se trata de processos narrativos que não configuram um modo de expressão individual, mas sobretudo coletiva, cultural e identitária, atendendo ao jogo de coqueteria que o próprio autocolante expressa, entre o que vai mostrando aos outros e o que deles vai camuflando.

O segundo bloco de textos, versando mais sobre as questões da cultura e dos universos tecnológicos, integra quatro textos.

As tecnologias digitais continuam a ser o foco do texto da autoria de Francisco Conrado e Luís Santos. Os autores propõem uma visão reflexiva sobre o crescimento da tecnologia do second screen, como resultado do aumento significativo de investimento por parte de grandes operadores televisivos. Na análise empreendida sobre a oferta existente em torno dessa tecnologia, os autores evidenciam as suas potencialidades, associadas principalmente a produtos de entretenimento e comércio eletrónico.

Por sua vez, Catarina Sales cruza os resultados obtidos por meio de diversas técnicas e propõe, nesta base, uma compreensão possível dos intervalos de tempo que medeiam a passagem da duração nos transportes usados diariamente. Perspetivando as implicações das tecnologias de informação e comunicação nas esferas da sociabilidade, do trabalho e em outras esferas, a autora discorre sobre o modo como as tecnologias favorecem a apropriação total do tempo, sem que o espaço seja relevante.

Entretanto, a comparação entre emissoras ibéricas constitui o foco do texto escrito por Teresa Piñeiro-Otero e Fábio Ribeiro. Os autores desenvolvem uma análise exploratória sobre as políticas atuais das principais rádios espanholas e portuguesas nas aplicações móveis, buscando avaliar o grau de interação e participação mobilizado nessas plataformas. Entre as principais constatações, destacam que a plataforma móvel representa mais um canal suplementar para a rádio tradicional FM, do que um novo meio com linguagem e expressividade próprias.

Finalmente, Saleta de Salvador Agra e Yolanda Martínez Suárez apresentam os resultados de um estudo de caso sobre ontologia móvel e tecno-cidadania indígena, realizado com a comunidade indígena Shuar, no sul da província equatorial da Amazónia (Zamora Chinchipe), Equador. A partir de reflexões sobre apropriação dos telefones móveis por integrantes dessa comunidade, as autoras evidenciam e analisam o desencadeamento de uma série de particularidades, no que respeita à conceção espaciotemporal, assim como aos processos de configuração identitária do povo Shuar.

Na seção "Varia" são apresentados dois textos que questionam diretamente o mercado internacional do trabalho, a utilização das tecnologias digitais e as transformações das relações de produção, a nível global.

Teresa Cristina Furtado Matos e Serge Katembera Rhukuzage descontroem alguns dos mecanismos implicitos de dominação, que caraterizam as relações entre países do 
Sul e países do Norte, no caso concreto das atividades informacionais. Os autores analisam as experiências subjetivas de bloggers que trabalham para uma empresa francesa, a partir de vários países de África, evidenciando que, para a maior parte, trabalhar numa base não remunerada para empresas ocidentais, significa um passo em frente na obtenção de visibilidade e reconhecimento profissional, os quais são perspetivados como uma fase no desenvolvimento da carreira. Assinalando o modo como alguns destes bloggers assumem a condição de subvalorização em que se encontram, o texto deixa várias questões em aberto, relevantes para pensar o modo como se urdem as relações de produção num mundo global, e também a mobilização de pressupostos neoliberais relativamente à capitalização e circulação do conhecimento e da informação.

Por sua vez, o texto de Izabela Wagner cruza diversas abordagens metodológicas, sintetizando, de certa forma, as grandes problemáticas em redor das quais se situam os textos precedentes, dado que elucida as facetas não ditas ou implícitas da mobilidade de investigadores, sobretudo dos que se movem da Europa para os Estados Unidos da América, à procura de melhores condições de carreira e, portanto, de reconhecimento. A observação participante, juntamente com informação proveniente de entrevistas, faculta a empiria necessária para a construção de uma abordagem sobre a mobilidade de investigadores. Esta abordagem evidencia a dificuldade dos investigadores encontrarem mecanismos de seleção e de promoção justos nos Estados Unidos da América, face às diferenças que demonstram em relação ao que denominam como "caraterísticas auxiliares". Estas referem-se a qualidades que, não estando diretamente inscritas no trabalho científico, acabam por influir na construção de uma representação sobre a competência e a adequação ao posto de trabalho.

Por fim, apresentam-se duas recensões, uma da autoria de Diogo Cunha, sobre A Sociedade do Cansaço, livro escrito por Byung-Chul Han e a outra, da autoria de Esser Silva, acerca da obra Capitalismo Estético na Era da Globalização, de Lipovetsky e Serroy. Respeitando, ambas, a obra e o contexto de produção, de uma e outra, as recensões apresentadas encerram este número de modo ajustado, ao evidenciarem dois dos principais eixos condutores da mobilidade, para além da ênfase colocada nos usos dos média: por um lado, a experiência subjetiva do tempo e a contradição do capital, no sentido da extração da máxima rentabilidade do tempo humano; por outro, a intrínseca relação entre o capitalismo financeiro e global e as reconfigurações estéticas. Movendo-se todos de comum acordo, oleiam a continuidade das relações de consumo e dependência, desde os níveis micro ao macro.

\section{REFERÊNCIAS}

Appadurai, A. (1996). Modernity at large. Minneapolis: University of Minnesota Press.

Bauman, Z. (2004). Amor líquido. Rio de Janeiro: Jorge Zahar.

De Certeau, M. (1990). L'Invention du quotidien. Arts de faire. Paris: Gallimard. 
Gehardi, L. (2009). La mobilité ambigue - Espace, temps et pouvoir aux sommets de la société contemporaine. Paris: Éditions Universitaires Européenes.

Gehardi, L. \& Pierre, P. (2013). Geographic mobility as a system of power relations inside business networks. Perspectives on Global Development and Technology, 12(4), 514- 530.

Hall, S. (1997). The centrality of culture: notes on the cultural revolutions of our time. In K. Thompson (ed.). Media and Cultural Regulation (pp.207-238). Londres: Thousand Oaks.

King, R. \& Wood, N. (Eds.) (2001). Media and migration: Constructions of mobility and difference. Londres: Routledge.

Nurse, L. (2014). Creative Applications of Biographical Research: Theory, Practice and Policy. Acedido em http:// www.europeansociology.org/docs/RNs/RN3/Biographical\%20Perspectives\%200n\%20European\%20 Societies\%20FINAL\%20Booklet\%20\%281\%29.pdf

Sheller, M. \& Urry, J. (2006). The new mobilities paradigm. Environmental Planning, 38(2) 207-226.

Sheller, M. (2011). Mobility. Sociopedia.isa, Doi: 10.1177/205684601163.

Wolley, A. (2014). Contemporary asylum narratives: Representing refugees in the twenty-first century. Basingstoke: Palgrave. Acedido em https://books.google.pt

\section{NOTAS BIOGRÁFICAS}

Emília Araújo é investigadora integrada no CECS - Centro de Estudos de Comunicação e Sociedade. É docente no departamento de Sociologia da Universidade do Minho e tem trabalhado na área da sociologia da cultura, da ciência e do tempo.

E-mail: emiliararaujo@gmail.com

Instituto de Ciências Sociais, Universidade do Minho, 4710-057-Braga, Portugal

Denise Cogo é Professora Titular do Programa de Pós-Graduação em Comunicação e Práticas de Consumo da Escola Superior de Propaganda e Marketing (ESPM), São Paulo, Brasil e investigadora do Conselho Nacional de Desenvolvimento Científico e Tecnológico (CNPq).

E-mail: denisecogo2@gmail.com

ESPM - Campus Francisco Gracioso, Rua Dr. Álvaro Alvim, $123-4^{\circ}$ andar - Bloco C- Vila Mariana - São Paulo / SP - Brasil - CEP 04018-010

Manuel Pinto é Professor e investigador do Instituto de Ciências Sociais da Universidade do Minho, onde desenvolve trabalho nas áreas de literacia informativa e mediática, sociologia do jornalismo e políticas de comunicação. É diretor do Programa Doutoral de Ciências da Comunicação e diretor da linha de pesquisa de Media e Jornalismo do Centro de Estudos de Comunicação e Sociedade.

E-mail:mjspinto@gmail.com

Instituto de Ciências Sociais, Universidade do Minho, 4710-057-Braga, Portugal 